\title{
Montreal electronic artificial urinary sphincters: Our futuristic alternatives to the AMS800 ${ }^{\mathrm{TM}}$
}

\author{
Xavier Biardeau, $M D^{\prime}$; Sami Hached, $M D^{2}$; Oleg Loutochin, $M D^{1}$; Lysanne Campeau, MD'; \\ Mohamad Sawan, $M D^{2}$; Jacques Corcos, $M D^{1}$
}

Jewish General Hospital, McGill University; 2 Unversité de Montréal; Montreal, QC, Canada

Cite as: Can Urol Assoc J 2017;11 (10):E396-404. http://dx.doi.org/10.5489/cuaj.4493 Published online October 10, 2017

\section{Abstract}

Introduction: We aimed to present three novel remotely controlled hydromechanical artificial urinary sphincters (AUSs) and report their in-vitro and ex-vivo results.

Methods: We successively developed three distinct hydrome-

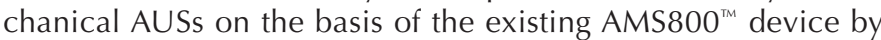
incorporating an electronic pump. No changes were made to the cuff and balloon. The AUS\#1 was designed as an electromagnetically controlled device. The AUS\#2 and AUS\#3 were conceived as Bluetooth 2.1 remotely controlled and Bluetooth 4.0 remotelycontrolled, adaptive devices, respectively. In-vitro experiments profiled occlusive cuff pressure (OCP) during a complete device cycle, with different predetermined OCP. Ex-vivo experiments were performed on a fresh pig bladder with $4 \mathrm{~cm}$ cuff placed around the urethra. Leak point pressure with different predetermined OCP values was successively measured during cystometry via a catheter at the bladder dome.

Results: Our in-vitro and ex-vivo experiments demonstrated that these three novel AUSs provided stable and predetermined OCP — within the physiological range - and completely deflated the cuff, when required, in a limited time compatible with physiological voiding cycles.

Conclusions: Our three novel, remotely controlled AUSs showed promising results that should be confirmed by in-vivo experiments focusing on efficacy and safety.

\section{Introduction}

Artificial urinary sphincter (AUS) implantation is considered the gold standard for treating severe stress urinary incontinence. ${ }^{1}$ Initially described in 1947 by Foley, ${ }^{2}$ the concept was developed and introduced on the market in 1973 by American Medical System Holdings Inc. (Minnetonka, MN, U.S.) under the name AS721 ${ }^{\text {TM }}$. Since then, the device has been improved several times, leading to the AMS800 ${ }^{\mathrm{TM}}$, the latest version that became available in 1983. Outcomes have been repeatedly reported to be acceptable, with longterm continence rates ranging from 59-97\% and patient satisfaction rising from $77-90 \%{ }^{3}$ however, urethral atrophy (4-10\%), delayed erosion (4-10\%), and AUS mechanical dysfunction (7.6-21\%) are frequent, and responsible for high explantation rates. ${ }^{3}$ Surgical revision has been evaluated to be about $60 \%$ at 10 years. ${ }^{4}$ The normal manual dexterity needed for pump manipulation and the non-adjustable pressure regimen within the cuff have been identified as important limitations. ${ }^{5,6}$ Influenced by this rationale, few authors have developed novel AUSs to improve the AMS800.5,7-13

Here, we present three distinct AMS800 retro-compatible pumping systems: the AUS\#1, AUS\#2, and AUS\#3, developed recently as a collaborative work between McGill University and École polytechnique de Montréal. Our approach was to improve the AMS800 by incorporating a remotely controlled electronic pump without modifying the cuff and pressure-regulating balloon (PRB). Data on our prototype pressure regulation hardware — the wireless connection device and different energy supply systems - have already been reported recently in engineering journals. ${ }^{14-16}$

In the present article, we describe these three distinctly developed systems from clinicians' viewpoints and in a language accessible to non-engineers. We focus mainly on pressure issues associated with each of them in in-vitro and ex-vivo experiments.

\section{Methods}

\section{Devices}

\subsection{AMS800}

The AMS800 is a hydromechanical implant that partially mimics the behaviour of normal urinary sphincters (Fig. 1A). It is a three-piece device that includes a pump, cuff and PRB made of silicone interconnected by $3 \mathrm{~mm}$ diameter tubes, usually filled with saline solution. The cuff (3.5-11.5 
$\mathrm{cm}$ diameter) circumscribes the urethra or bladder neck. When inflated, it is designed to exert constant predetermined occlusive cuff pressure (OCP) all around the urethra, ensuring urinary continence. In contrast, when the cuff is deflated, the OCP decreases close to $0 \mathrm{cmH}_{2} \mathrm{O}$ and lets the urethra open to allow bladder emptying. The PRB determines OCP (51-60 $\mathrm{cmH}_{2} \mathrm{O}, 61-70 \mathrm{cmH}_{2} \mathrm{O}$, and 71-80 $\mathrm{cmH}_{2} \mathrm{O}$ ).

The pump has two distinct parts. The top part contains a deactivation button that blocks the cuff in a deflated state. The lower part consists of a compressible button that can be pressed manually to deflate the cuff. This manipulation induces solution transfer from the cuff to the PRB, allowing the device to pass from the "closed" to the "open" state for approximately two minutes, after which pressure re-equilibrates passively between the PRB and the cuff, due to a hydraulic resistor located in the pump.

\subsection{AUS\#I (an electromagnetically controlled device)}

The AUS\# 1 has been designed to replace the manual pump with a unidirectional, magnetically controlled pump to make it implantable in less skilled patients (Fig. 1B). The "hydraulic" module includes a piezoelectric micropump and a hydraulic resistor mounted in parallel. The unidirectional piezoelectric micropump (MBP-2115BD, Microbase Technology Co., Taoyuan, Taiwan) has a large flow capacity of $15 \mathrm{ml} / \mathrm{min}$ with maximum backpressure of $254 \mathrm{cmH}_{2} \mathrm{O}$ and maximum suction pressure of $102 \mathrm{cmH}_{2} \mathrm{O}$. A primary, certified, implantable lithium thionyl chloride cell (LTC15MC-S1, EaglePitcher Medical Power, Plano, TX, U.S.), providing 16-year autonomy (assuming an average of seven micturitions per day), powers the "control unit."

To regulate the pump, a sensitive reed switch was integrated in the system, permitting the sphincter to be operated by advancing a small neodymium magnet to the reed switch. Cuff opening is indicated by a low sound emitted by a buzzer, confirming that the pump is powered on. The components are assembled in a biocompatible, siliconecoated acrylonitrile butadiene styrene (ABS) case $(30 \mathrm{~mm}$ $\times 20 \mathrm{~mm} \times 58 \mathrm{~mm}$ ) and replace the manual pump. This pumping system can also be mounted on an AMS800 by removing the hydraulic resistor and placing the device in

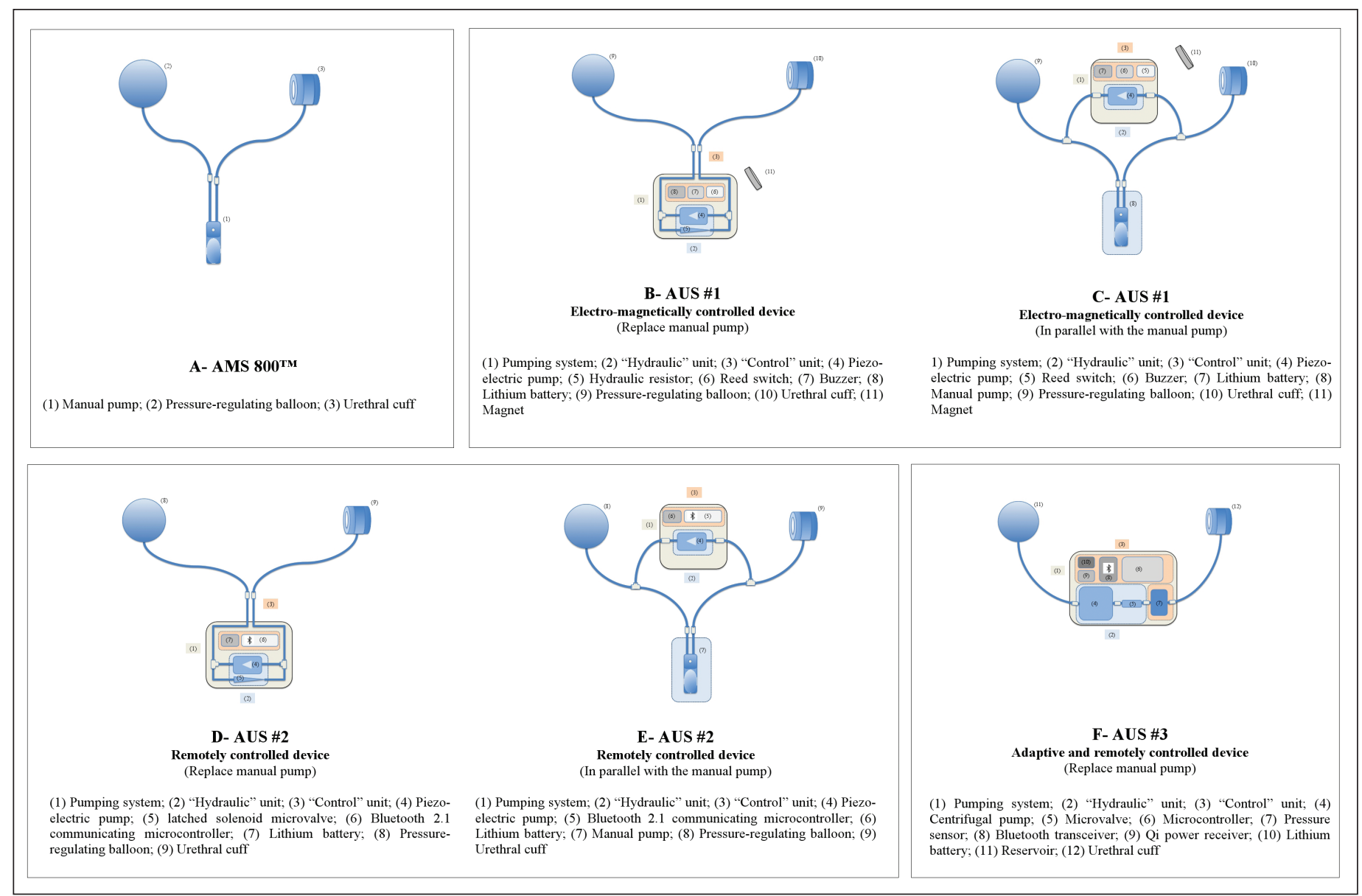

Fig. 1. Simplified schemas. (A) AMS800'M; (B) AUS\#1: Replacing the manual pump; (C) AUS\#1: Connected in parallel with the manual pump; (D) AUS\#2: Replacing the manual pump; (E) AUS\#2: Connected in parallel with the manual pump; (F) AUS\#3: Replacing the manual pump. 
parallel with the manual pump as an extension. Here, the hydraulic resistor of the manual pump allows cuff refilling (Fig. 1C), making the AUS\#1 both a manually and electromagnetically controlled device. It also offers the opportunity to deactivate the sphincter by pushing the deactivation button on the top part of the AMS800 manual pump. System operation is described in Fig. 2A.

\subsection{AUS\#2 (a remotely controlled device)}

The AUS\#2 was designed to replace the initial manual pump with a remotely controlled pumping system, allowing implantation in less skilled patients and enabling wireless deactivation of the AUS (Fig. 1D). The hydraulic module is the same as the one described previously for the AUS\#1; however, the hydraulic resistor is replaced by a latched solenoid microvalve (LHLA0531411H, The Lee Company, Westbrook, CT, U.S.). The control unit includes a Bluetooth 2.1 communicating microcontroller (AIRCable SMD, Wireless Cables Inc., San Jose, CA, U.S.) for wireless communication with a previously developed control interface, as well as a rechargeable lithium battery providing 41-day autonomy (assuming an average of seven micturitions per day). The components are assembled in an ABS case $(50 \mathrm{~mm} \times 50 \mathrm{~mm} \times 20 \mathrm{~mm})$ and replace the manual pump. As with the AUS\#1, this system can be mounted in parallel with the AMS800 manual pump (Fig. 1E). System operation is described in Fig. 2B.

\subsection{AUS\#3 (a remotely controlled, adaptive device)}

The AUS\#3 was designed to replace the initial manual pump with an adaptive, remotely-controlled pumping system (Fig. 1F). This novel device provides: 1) OCP adjustment in a real-time manner; 2) wireless remote communication for continuous pressure regulation; 3 ) extended battery life with a wireless power delivery system based on an inductive power standard (Qi). The hydraulic module is composed of a centrifugal pump (M200S, TCS Micropumps, Kent, U.K.) and a latched solenoid microvalve (LHLA0531411H, The Lee Company). The M200S centrifugal pump delivers maximal head pressure of $240 \mathrm{cmH}_{2} \mathrm{O}$, and flow capacity reaches 700 $\mathrm{ml} / \mathrm{min}$. The valve only needs a maximum of $10 \mathrm{~ms}$ for state change, providing rapid cuff sealing after inflation.

It is important to note that, in contrast to the AMS800, the balloon is not pressurized but only serves as a reservoir. The control unit is responsible for operating the hydraulic microactuators, undertaking extra tasks, wireless communication, supervision, and control. It integrates a microcontroller, a differential pressure sensor and a Bluetooth 4.0 low-energy transceiver. The pressure sensor (RQOM100D, First Sensor AG, Berlin, Germany) monitors differential operating pressures between 0 and $101.97 \mathrm{cmH}_{2} \mathrm{O}$. The Bluetooth 4.0 low-energy transceiver (ISP091201, Insight SiP, Sophia-Antipolis, France) ensures wireless communication with a previously developed control interface. This interface, configured on computer and smartphone, gives real-time microactuator control and implant parameter supervision. The time required to establish connection between the Bluetooth 4.0 transceiver and the interface has been previously estimated to be less than one second. The microcontroller (PIC24F16KA102, Microchip Technology Inc., Chandler, AZ, U.S.) controls the whole pumping system, safeguarding transition from the "open" to the "closed" state. Power consumption of the control unit is minimized with this reported architectural design, giving approximate autonomy of 10 months, with a rechargeable lithium battery (GMB053040, Guangzhou Markyn Battery Co., Guangdong, China) and a rechargeable Ni-MH battery ( $\mathrm{V} 80 \mathrm{H}$, VARTA Microbattery $\mathrm{GmbH}$, Ellwangen, Germany).

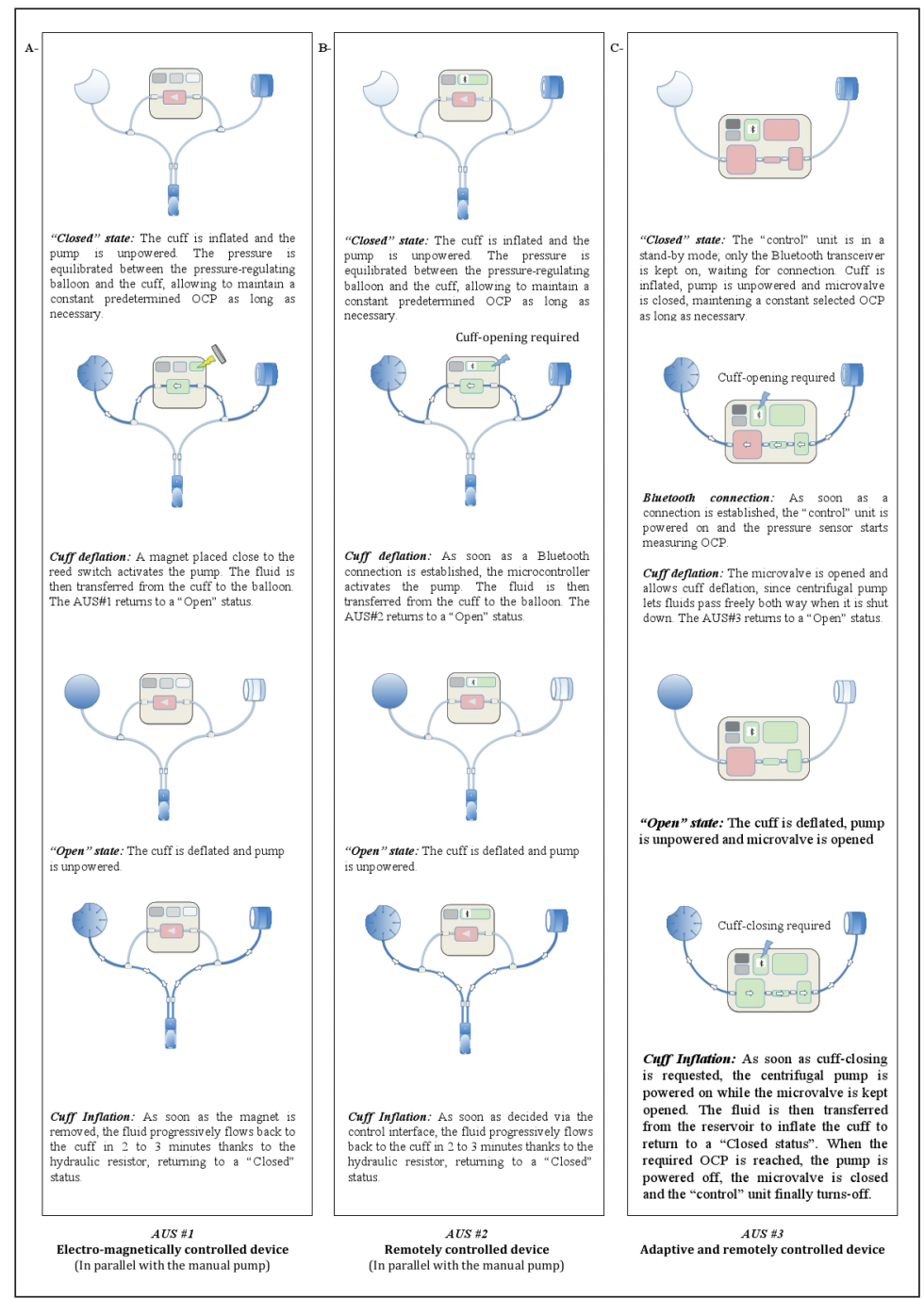

Fig. 2. System operation: (A) AUS\#1; (B) AUS\#2; (C) AUS\#3. 
To provide longer device lifespan through regular and easy battery reloading, we added a wireless power delivery system based on Qi, an international interoperable standard for wireless charging consisting of a power transmitter (placed outside the patient) and a receiver (placed inside the implanted medical device) magnetically coupled in less than two seconds when positioned close to each other (typically $5 \mathrm{~mm}) .{ }^{14}$ The components are assembled in an ABS case (50 $\mathrm{mm} \times 50 \mathrm{~mm} \times 20 \mathrm{~mm}$ ), replacing the initial manual pump. System operation is described in Fig. 2C.

\section{In-vitro and ex-vivo OCP assessment}

Each of the three devices was tested in-vitro and ex-vivo to verify that the pumping systems were able to: 1) provide stable, predetermined OCP to ensure continence, when required; 2 ) completely deflate the cuff and guarantee null OCP when micturition is desired; and 3) pass from the "closed" to the "open" state in a limited time compatible with physiological voiding cycles.

\subsection{In-vitro OCP evolution}

\subsubsection{AUS\#1 and AUS\#2}

The AUS\#1 and AUS\#2 were evaluated by the same methodology. They were both connected to a $4 \mathrm{~cm}$ AMS occlusive cuff on one side and to an AMS PRB on the other side. The hydraulic resistor of the AUS\#1 was adjusted to allow two- to three-minute closing time duration. The occlusive cuff was then placed around an $8 \mathrm{~mm}$ plastic rod and tested at different pressure levels $\left(\mathrm{P} 1=54 \mathrm{cmH}_{2} \mathrm{O} ; \mathrm{P} 2=60 \mathrm{cmH}_{2} \mathrm{O} ; \mathrm{P} 3=72\right.$ $\left.\mathrm{cmH}_{2} \mathrm{O} ; \mathrm{P} 4=80 \mathrm{cmH}_{2} \mathrm{O} ; \mathrm{P} 5=91 \mathrm{cmH}_{2} \mathrm{O}\right)$. The AUS $\# 1$ was operated by magnet in contact with the reed switch and initially inflated cuff. The magnet was kept in place during five seconds for cuff deflation and was then removed, allowing the cuff to gradually re-close. Similarly, the AUS $\# 2$ was operated remotely by computer. Connection was initially established with a "closed" state device and, after complete cuff deflation, the AUS\#2 was required to stay open for one consecutive minute before re-inflation. OCP was recorded throughout the procedure for each pressure level, by an atmospherereferenced pressure sensor (RQOM100D, First Sensor AG, Berlin, Germany) connected to the circuit close to the cuff.

\subsubsection{AUS\#3}

The AUS\#3 was connected to a $4 \mathrm{~cm}$ AMS occlusive cuff on one side and to an AMS PRB - partially filled with saline solution acting as a simple fluid reservoir — on the other side. The occlusive cuff was then placed around an $8 \mathrm{~mm}$ plastic rod and different pressure levels were tested $\left(\mathrm{P}^{\prime}=15 \mathrm{cmH}_{2} \mathrm{O} ; \mathrm{P} 2^{\prime}=30 \mathrm{cmH}_{2} \mathrm{O} ; \mathrm{P}^{\prime}=50 \mathrm{cmH}_{2} \mathrm{O} ; \mathrm{P}^{\prime}=70\right.$
$\mathrm{cmH}_{2} \mathrm{O} ; \mathrm{P}^{\prime}=90 \mathrm{cmH}_{2} \mathrm{O}$ ). The AUS\#3 was operated remotely by computer for each pressure level. Connection was initially established with a "closed" state device. The cuff was then deflated and kept open for 10 consecutive seconds before being re-inflated. For each pressure level, OCP was acquired throughout the procedure from the pressure sensor implanted in the "control" unit.

\subsection{Ex-vivo $O C P$ assessment}

\subsubsection{AUS\#1 and AUS\#2}

Once again, because of the resemblance between AUS\#1 and AUS\#2, OCP was assessed in an ex-vivo fresh pig bladder model by the same methodology. They were both equipped with a 51-60 $\mathrm{cmH}_{2} \mathrm{O}$ PRB. The cuff was placed and inflated around the urethra while an $8 \mathrm{Fr}$ twin-lumen catheter was inserted through the bladder dome and secured by 3/0 silk purse-string suture. A two-way stop-cock valve was connected to the catheter. The bladder was then filled with saline solution via one of the two stop-cock valves, and intravesical pressure was measured through the second valve by highsensitivity pressure transducer (AD Instruments Inc., Colorado Springs, CO, U.S.). The transducer was placed at the level of the inflated cuff and connected to a computer for continuous monitoring of intravesical pressure with a Powerlab 4/30 chart system (AD Instruments Inc.). Intravesical pressure was initially increased by saline solution infusion until $50 \mathrm{cmH}_{2} \mathrm{O}$, then raised manually and recorded continuously until leak point pressure (LPP) was reached. This step was repeated several times to ensure the reliability of our measures. The bladder was finally re-inflated to obtain $40 \mathrm{cmH}_{2} \mathrm{O}$ intravesical pressure and the cuff was opened.

\subsubsection{AUS\#3}

The AUS\#3 was assessed similarly in an ex-vivo model: fresh pig bladder. It was operated remotely by computer and different OCP were set successively $\left(\mathrm{P} 1^{\prime \prime}=20 \mathrm{cmH}_{2} \mathrm{O} ; \mathrm{P} 2^{\prime \prime}=30\right.$ $\mathrm{cmH}_{2} \mathrm{O} ; \mathrm{P}^{\prime \prime}=40 \mathrm{cmH}_{2} \mathrm{O} ; \mathrm{P}^{\prime \prime}=50 \mathrm{cmH}_{2} \mathrm{O} ; \mathrm{P}^{\prime \prime}=60 \mathrm{cmH}_{2} \mathrm{O}$; $\mathrm{P}^{\prime \prime}=70 \mathrm{cmH}_{2} \mathrm{O} ; \mathrm{P}^{\prime \prime}=80 \mathrm{cmH}_{2} \mathrm{O}$ ). For each of the different cuff pressure settings, intravesical pressure was increased manually and recorded continuously until LPP was reached.

\section{Results}

\section{In-vitro OCP evolution}

\subsection{AUS\#1 and AUS\#2 (Fig. 3)}

The AUS\#1 and AUS\#2 pumping systems were able to maintain constant OCP when not operated and the cuff within 


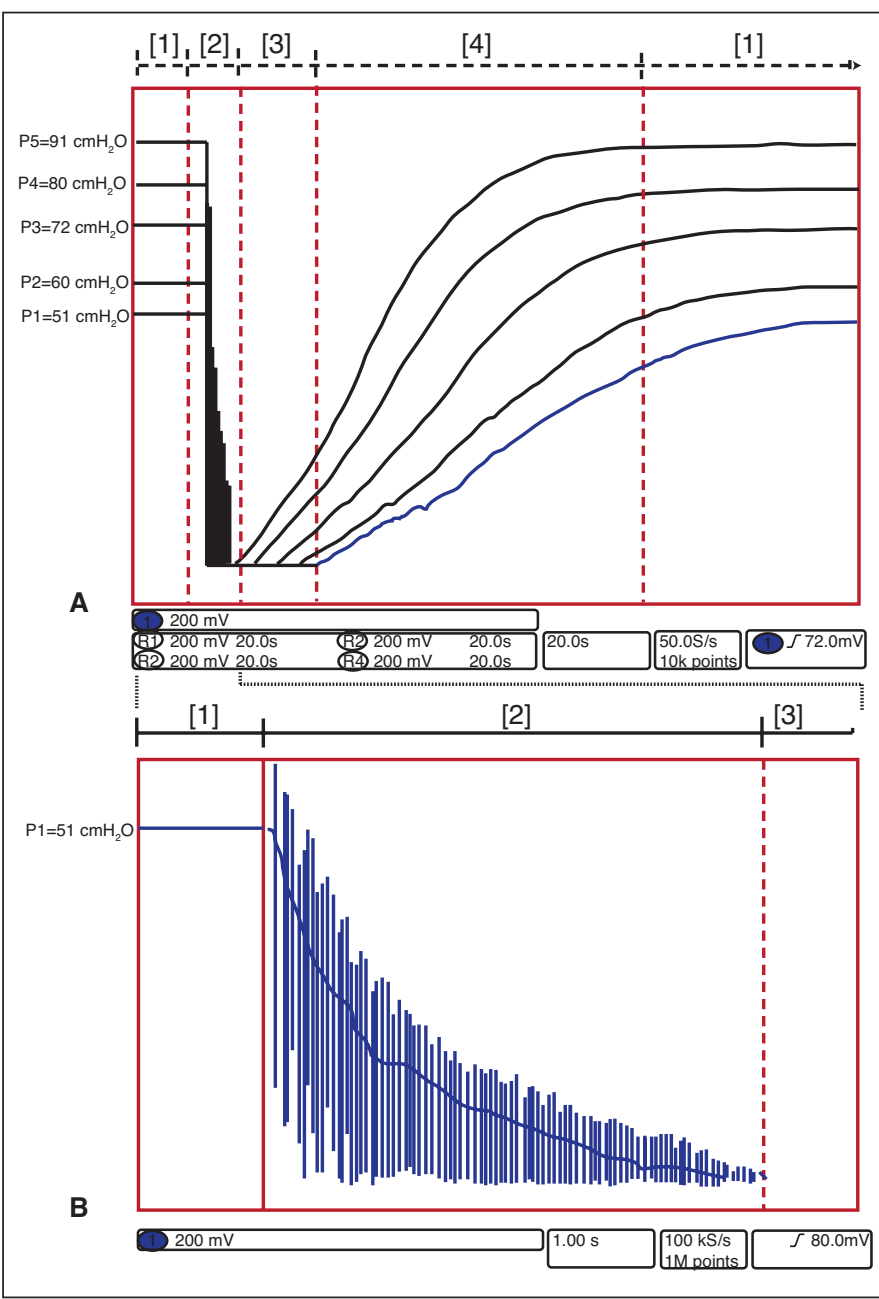

Fig. 3. In-vitro assessment of the AUS\#1 occlusive cuff pressure (OCP) profile: $(\boldsymbol{A})$ during a complete device cycle; and $(\boldsymbol{B})$ during the cuff deflation. Notes: [1] "Closed" state: Initially, the pressure within the system is balanced. The cuff is full with fluid and at pressure-regulating balloon's (PRB) pressure. [2] Cuff deflation: To turn on the pumping system, the magnet is placed close to the control unit. Then the OCP starts to drop. During the two seconds of pumping, the effect of a displacement pumping mechanism is visible (B). [3] "Open" state: The OCP is below the atmospheric pressure. [4] Cuff inflation and return to "closed" state: Under the PRB's pressure, the fluid gradually flows back from the balloon to the cuff through the hydraulic resistor. After 2-3 minutes, the pressure between the balloon and the cuff is completely balanced, closing the urethra consequently.

two seconds when operated, with an OCP kept null as long as required. For both pumping systems, the hydraulic resistor permitted cuff inflation within the following 2-3 minutes until pressure equilibration between the cuff and balloon was reached. No significant pressure spikes or unsteady pressure behaviours were detected for both devices. These results were observed with all pressures tested (P1-P5).

\subsection{AUS\#3 (Fig. 4)}

Similarly, the AUS\#3 pumping system was able to provide and maintain OCP throughout the procedure and completely deflate the cuff when required. No significant pressure spikes or unsteady pressure behaviours were detected. These results were observed with all pressures tested (P1"-P7").

\section{Ex-vivo OCP evolution}

\subsection{AUS\#1 and AUS\#2 (Fig. 5)}

Using a 51-60 $\mathrm{cmH}_{2} 0-P R B$, LPP was measured between 60 and $63 \mathrm{cmH}_{2} \mathrm{O}$ for both AUS\#1 and AUS\#2 devices. As long as intravesical pressure was maintained under $60 \mathrm{cmH}_{2} \mathrm{O}$, no leakage occurred. When intravesical pressure increased over 60-63 $\mathrm{cmH}_{2} \mathrm{O}$, some leakage was observed, associated with a rapid decrease in intravesical pressure. After cuff deflation, intravesical pressure decreased rapidly (in a few seconds) close to $0 \mathrm{cmH}_{2} \mathrm{O}$ associated with complete bladder emptying, testifying to complete urethra opening.

\subsection{AUS\#3 (Fig. 6)}

Using a predetermined $\mathrm{P}^{\prime \prime}=80 \mathrm{cmH}_{2} \mathrm{O}$ OCP, LPP was measured between 80 and $85 \mathrm{cmH}_{2} \mathrm{O}$. As long as intravesical pressure was maintained under $80 \mathrm{cmH}_{2} \mathrm{O}$, no leakage occurred. When intravesical pressure increased over $80-85 \mathrm{cmH}_{2} \mathrm{O}$, some leakage was observed associated with a rapid decrease in intravesical pressure. These results were observed with all the other pressures tested (P2"-P6").

\section{Discussion}

Here, we present three different pumping systems aimed at improving the currently available AMS800 and focusing on pressure issues. They were all able to reach and sustain a predetermined OCP to maintain urinary continence and rapidly and completely deflated the cuff when bladder emptying was necessary, entirely satisfying the required specifications in terms of OCP profile. Compared to other novel AUSs currently in development, our three devices did not target complete replacement of the AMS800, but improved its performance and reduced the limitations associated with it (Table 1). Knowing that each component of the AMS800 is the result of a long and fastidious research process, ${ }^{17,18}$ we only modified the pumping system while preserving the existing cuff, PRB, and tubing. The objective was to produce a modified AMS800 implantable in less skilled patients with the possibility of adjusting pressure after implantation.

Even if no data are currently available, we have noticed, in our practice, that among patients who could theoretically benefit from an AMS800, a significant number will 


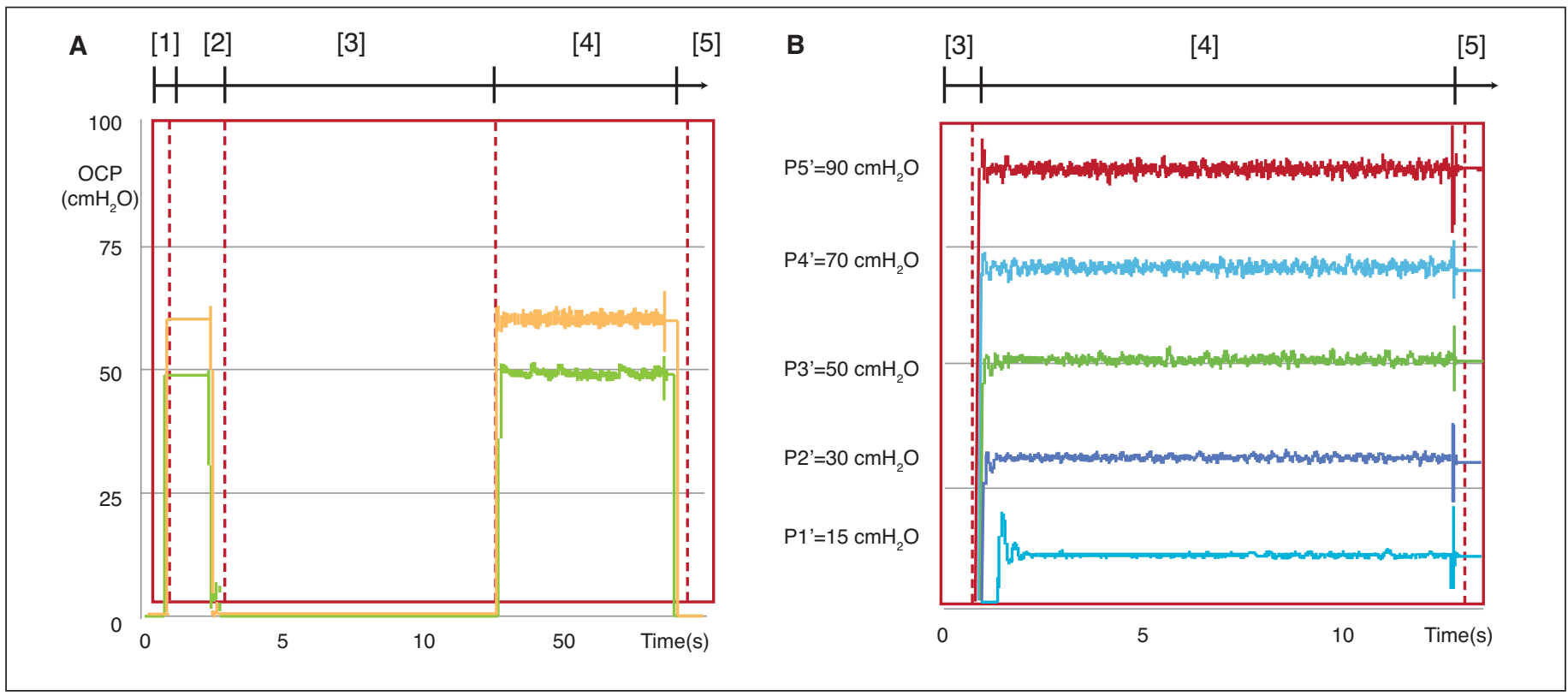

Fig. 4. In-vitro assessment of the AUS\#3 occlusive cuff pressure (OCP) profile. (A) OCP evolution recorded during a complete cycle; (B) Recorded OCP when the AUS\#3 device is "closed." Notes: [1] Stand-by mode: The control unit, including the pressure sensor, is powered down. No pressures are recorded. Only the transceiver is kept in a stand-by mode, waiting for connection. [2] Bluetooth connection: As soon as a connection is established (around two seconds after request), the control unit is powered up and the sensor starts measuring the OCP. [3] Cuff deflation (to "open" state): As a consequence of the cuff opening request, the valve is opened generating a passive fluid transfer from the cuff to the balloon, responsible for a fast OCP decrease. The null pressure within the cuff is kept as long as programmed (here, 10 seconds). [4] Cuff inflation (to "closed" state): As soon as the cuff closing is requested, the OCP regulation process starts and the pumping system quickly rises the OCP. The pressure is kept at the requested set point value for a programmed period (here, six seconds), after which the valve is finally closed. During this six-second period, the pressure sensor detects impulses engendered by the centrifugal pump. [5] Valve closing and return to stand-by mode: By blocking fluid transfer, the closed valve passively keeps the cuff constantly pressurized and allowed the "control" unit, including the pressure sensor, to power down for energy-saving. At the end, the transceiver comes back to stand-by mode, waiting for another connection.

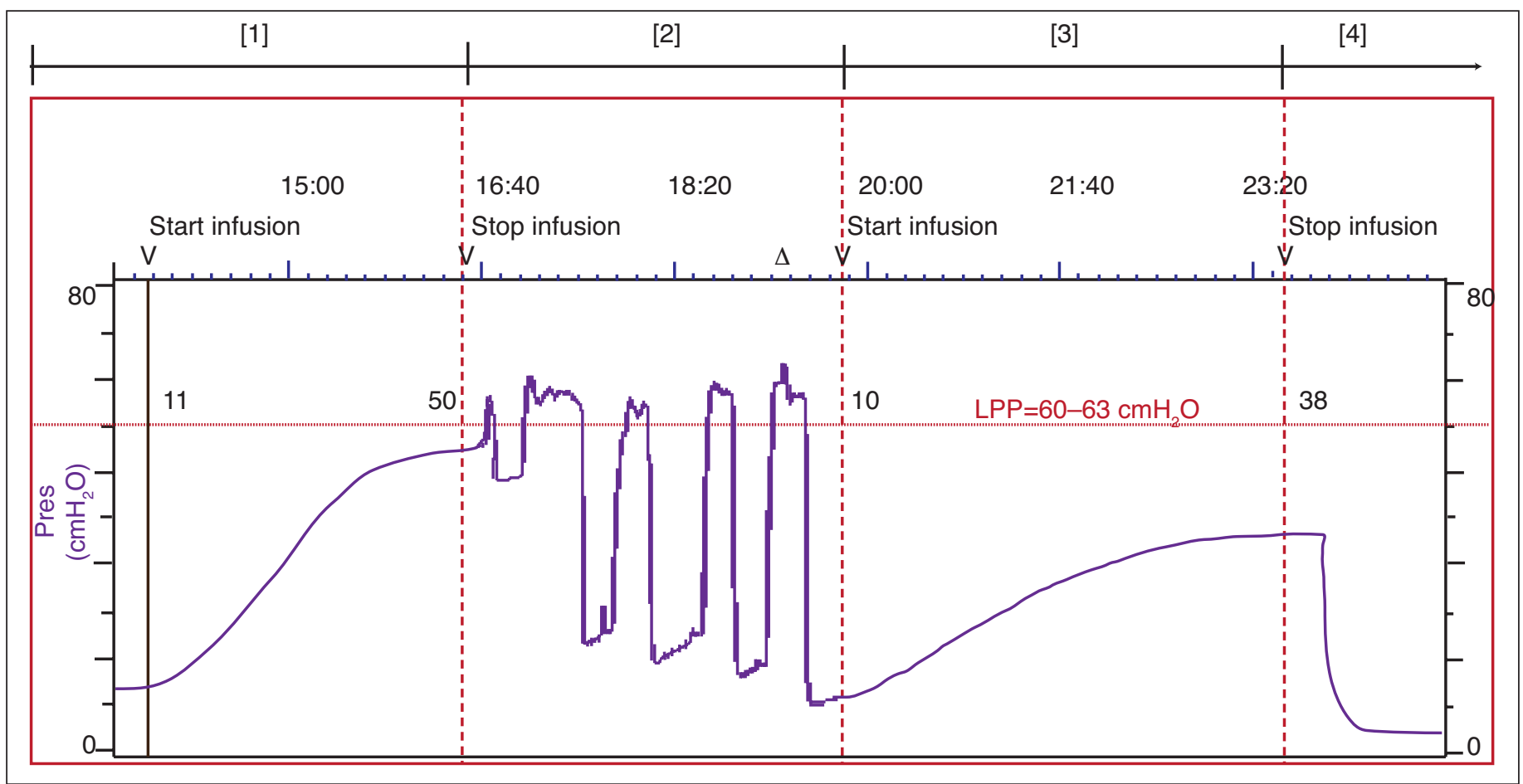

Fig. 5. Ex-vivo assessment of the AUS\#1 occlusive cuff pressure (OCP) using the leak point pressure (LPP). Notes: [1] Intravesical pressure is increased up to 50 $\mathrm{cmH} 20$ thanks to saline solution infusion. [2] Saline solution infusion is stopped and intravesical pressure is manually raised to reach the LPP. [3] Manual pressures are stopped and saline solution is infused again. [4] Magnet is placed close to the reed switch to deflate the cuff. 


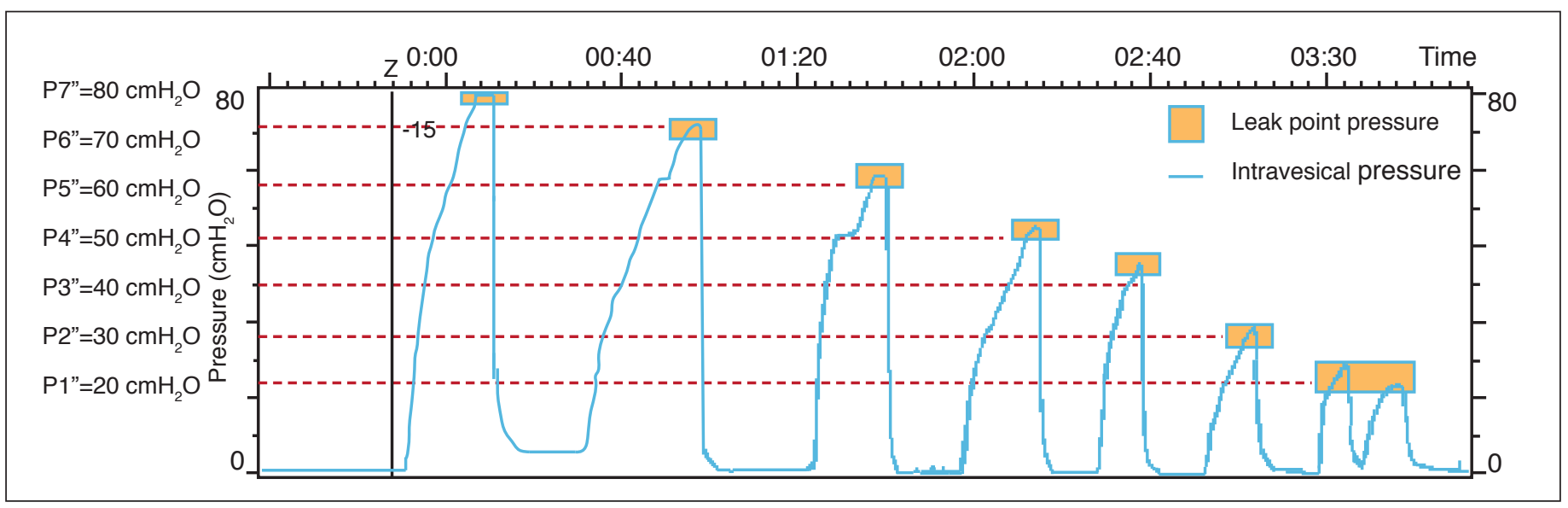

Fig. 6. Ex-vivo assessment of the AUS\#3 occlusive cuff pressure (OCP) using the leak point pressure (LPP).

not be implanted because of poor manual dexterity or difficulty in reaching the manual pump. Furthermore, these new pumping systems would be interesting in already-implanted patients showing loss of dexterity.

Finally, the possibility of adjusting cuff pressure postoperatively and in real-time would allow slight pressure increments in partially improved patients, as well as cuff deflation during the bedtime period to decrease pressure exerted on the urethra and reducing, in theory, the risk of erosion and atrophy. ${ }^{19}$ With volume going from 30 to $50 \mathrm{~cm}^{3}$, they are currently the smallest devices to incorporate an electronic pumping system ${ }^{10-13}$ with remote control ${ }^{13}$ (Table 1), making them easy to insert through the reservoir implantation incision and easily placed at the iliac fossa in a subcutaneous pouch. As pumping systems are currently handmade, device miniaturization is limited, especially because of $Y$ and $L$ suture-tie connectors at the hydraulic unit level. We can easily imagine that future industrial development will deliver a simpler and more compact design.

The AUS\#1 and AUS\#2 are certainly the simplest and closest to market. In the present article, we only showed the results associated with the AUS\#1. Since the AUS $\# 1$ and the AUS\#2 are nearly identical in terms of hydraulic unit and only differ from the control unit, the OCP profile is very similar in these two devices. In our practice, the magnet could correctly activate the reed switch up to $5 \mathrm{~cm}$. The AUS\#3 is the most complex, but undoubtedly linked with potential opportunities. In practice, two distinct interfaces will be developed. One for the urologist that will give full access to the sphincter features and a second interface for the patients, allowing opening and closing of the urethra, as well as OCP variation within limited ranges. The present battery needs to be recharged every 10 months of use through a wireless communicative implantable system. Due to its operation mechanism, the AUS\#3 cannot be equipped with a manual pump. For this reason, we are developing a safety feature consisting of a magnetic control system that could be connected to the operating system and allow cuff opening in case of remote controlling device unavailability. Similarly, we are currently working on new features to eliminate the AMS manual pump from AUS\# 1 and AUS\#2 without altering their size and shape. Regarding our current researches, overriding these limitations will probably need only simple modifications.

We agree with the fact that additional hardware insertion will undoubtedly increase the risk of device malfunction and site infection. Furthermore, in the present study, our three novel devices were only tested under in-vitro and ex-vivo conditions. Therefore, before any definitive conclusion, our promising results should be confirmed by in-vivo experiments, focusing on efficacy and safety associated with such devices.

Competing interests: The authors report no competing personal or financial interests.

This paper has been peer-reviewed.

\section{References}

1. Thüroff JW, Abrams P, Andersson KE, et al. EAU guidelines on urinary incontinence. Eur Urol 201 1;59:387400. hitps://doi.org/10.1016/i.eururo.2010.11.021

2. Foley FE. An artificial sphincter; a new device and operation for control of enuresis and urinary incontinence. J Urol 1947;58:250-9. https://doi.org/10.1016/S0022-5347(17)69552-1

3. Islah M, Cho SY, Son H. The current role of the artificial urinary sphincter in male and female urinary incontinence. World J Mens Health 2013;31:21-30. https://doi.org/10.5534/wimh.2013.31.1.21

4. Elliott DS, Barrett DM. Mayo Clinic long-term analysis of the functional durability of the AMS 800 artificial urinary sphincter: A review of 323 cases. J Urol 1998;159:1206-8. htrps://doi.org/10.1016/ S0022-5347(01)63557-2

5. Müller B, Deyhle H, Mushkolai S, et al. The challenges in artificial muscle research to treat incontinence. Swiss Med. Wkly 2009;139:591-5.

6. Chung E, Ranaweera M, Cartmill R. Newer and novel artificial urinary sphincters (AUS): The development of alternatives to the current AUS device. BJU Int 2012; 11 Supp14:5-11. https://doi.org/10.1111/i.1464410X.2012.11614.x

7. Knight SL, Susser J, Greenwell T, et al. A new arrificial urinary sphincter with conditional occlusion for stress urinary incontinence: Preliminary clinical results. Eur Urol 2006;50:57480. https://doi.org/10.1016/i. eururo.2006.03.065 


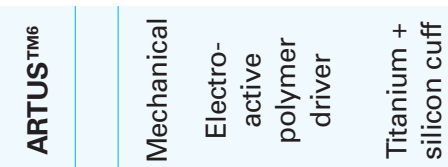

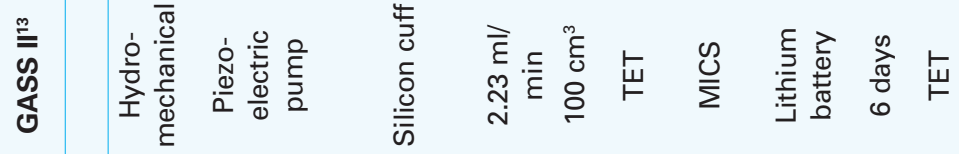

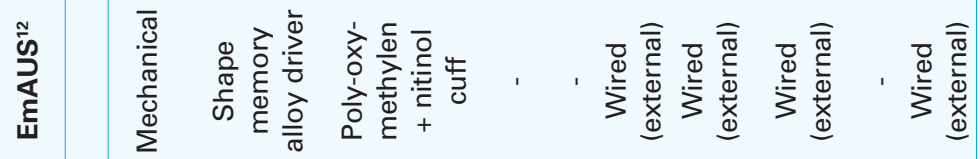

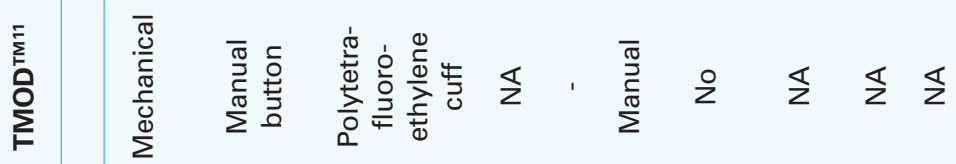

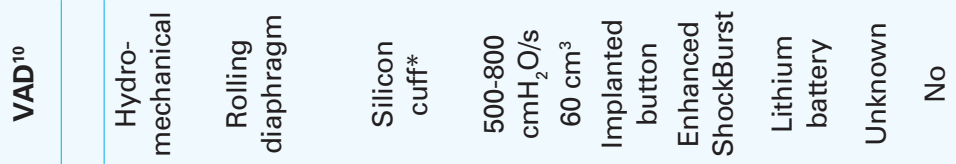

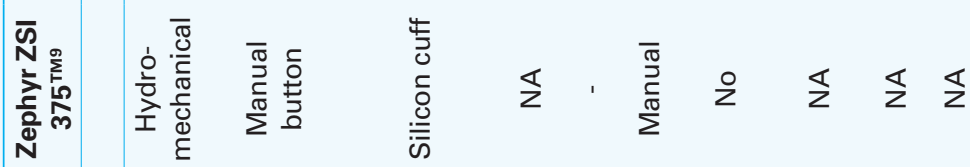

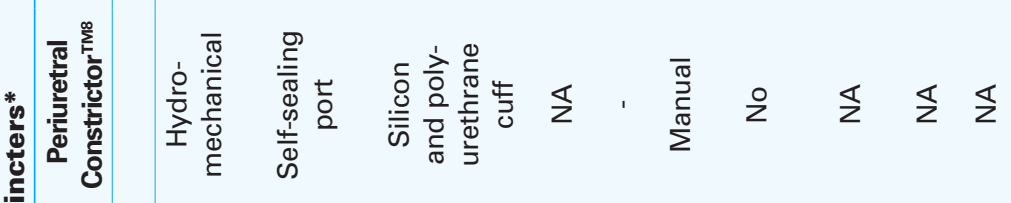

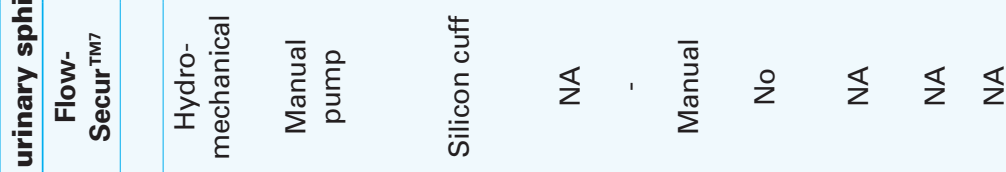

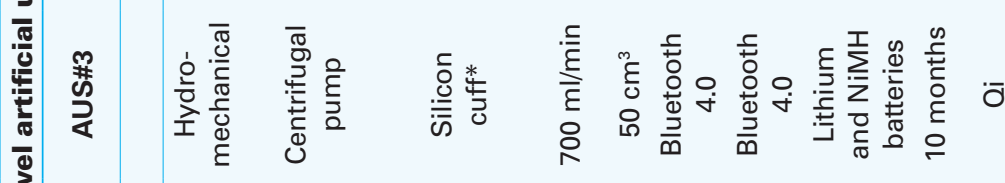

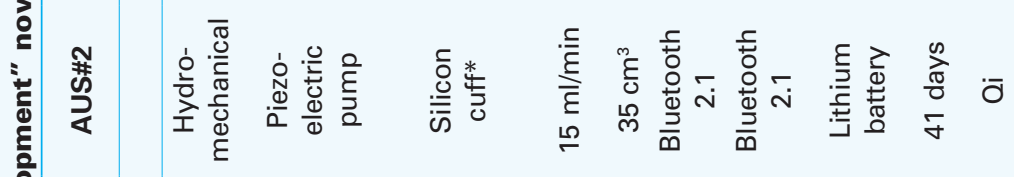

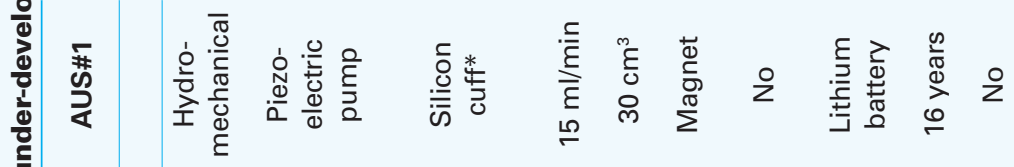

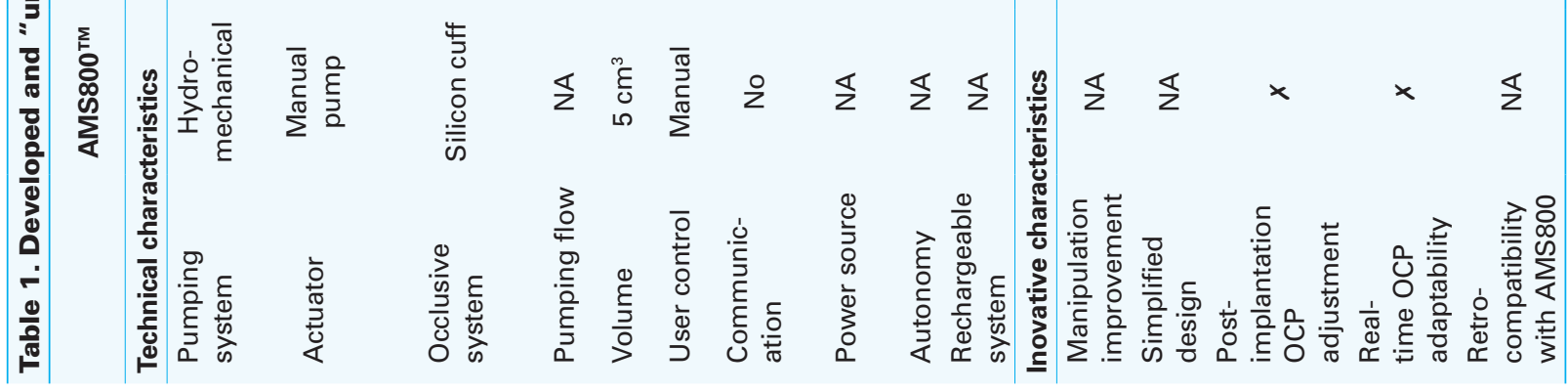




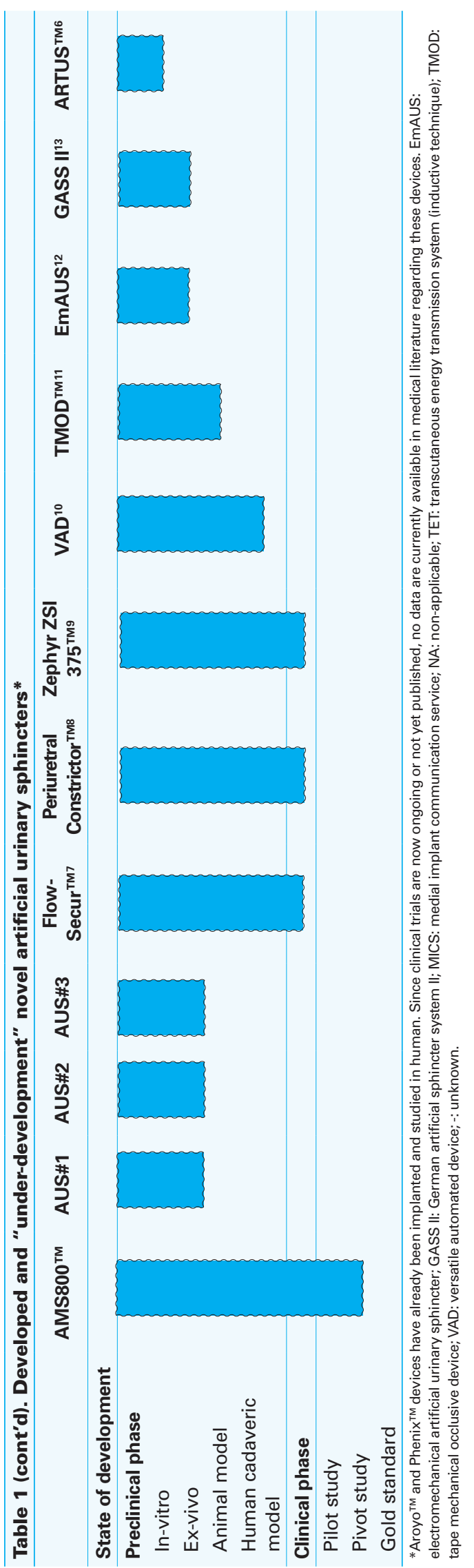

8. Schiavini JL, Damião R, De Resende Júnior JA, et al. Treatment of post-prostate surgery urinary incontinence with the periurethral constrictor: A retrospective analysis. Urology 2010;75:1488-92. https://doi.org/10.1016/i.urology.2009.12.078

9. Staerman $F, G$-Llorens $C$, Leon $P$, et al. ZSI 375 artificial urinary sphincter for male urinary incontinence: A preliminary study. BJU Int 2013;111:E202-6. https://doi.org/10.1111/i.1464-410X.2012.11468.x

10. Lamraoui $\mathrm{H}$, Bonvilain $\mathrm{A}$, Robain $\mathrm{G}$, et al. Development of a novel artificial urinary sphincter: A versatile automated device. Conf Proc IEEE Eng Med Biol Soc 2010;15:916-24. https://doi.org/10.1109/TMECH.2010.2056927

11. Malaeb BS, Elliott SP, Lee J, et al. Novel artificial urinary sphincter in the canine model: The tape mechanical occlusive device. Urology 2011;77:211-6. https://doi.org/10.1016/i.urology.2010.06.065

12. Valerio $M$, Jichlinski $P$, Dahlem $R$, et al. Experimental evaluation of an electromechanical artificial urinary sphincter in an animal model. BJU Int 2013;112:E337-43. https://doi.org/10.1111/i.1464-410X.2012.11728.x

13. Ruthmann 0 , Richter $S$, Seifert $G$, et al. The first tele-automatic low-voltage prosthesis with multiple therapeutic applications: A new version of the German artificial sphincter system. Artif Organs 2010;34:635-41. https:// doi.org/10.1111/j.1525-1594.2010.01004.x

14. Hached S, Trigui A, El Khalloufi I, et al. A Bluetooth-based low-energy Qi-compliant battery charger for implantable medical devices. In: 2014 IEEE International Symposium on Bioelectronics and Bioinformatics (ISBB). 2014; pp 1-4. https://doi.org/10.1109/ISBB.2014.6820911

15. Hached S, Saadaoui Z, Loutochin 0 , et al. Novel, wirelessly controlled, and adaptive artificial urinary sphincter. Conf Proc IEEE Eng Med Biol Soc 2015;1-13. https://doi.org/10.1109/TMECH.2015.2389254

16. Hached S, Loutochin 0 , Corcos J, et al. Novel, remotely controlled, artificial urinary sphincter: A retro-compatible device. Conf Proc IEEE Eng Med Biol Soc 2014; 19:1352-62. hitps://doi.org/10.1109/TMECH.2013.2280575

17. Light JK and Reynolds JC. Impact of the new cuff design on reliability of the AS800 artificial urinary sphincter. J Urol 1992;147:609-11. https://doi.org/10.1016/S0022-5347(17)37319-6

18. Leo ME, Barrett DM. Success of the narrow-backed cuff design of the AMS800 artificial urinary sphincter: Analysis of 144 patients. J Urol 1993;150:1412-4. https://doi.org/10.1016/S0022-5347(17)35793-2

19. Elliott DS, Barrett DM, Gohma $M$, et al. Does nocturnal deactivation of the artificial urinary sphincter lessen the risk of urethral atrophy? Urology 2001;57:1051-4. https://doi.org/10.1016/S0090-4295(01)00963-3

Correspondence: Dr. Jacques Corcos, Jewish General Hospital, McGill University, Montreal, QC, Canada; icorcos@jgh.mcgill.co 